\title{
A study of clinical and Immunofluorescence spectrum of Immunobullous diseases
}

\author{
Nitesh R. Pokharel', Anil Dev Pant ${ }^{2}$, Raghavendra Rao ${ }^{3}$, Surakchya Koirala ${ }^{4}$ \\ ${ }^{1}$ Consultant, Department of Dermatology, Grande International Hospital (GIH), Kathmandu, Nepal, ${ }^{2}$ Consultant, \\ Department of Pathology, Grande International Hospital (GIH), Kathmandu, Nepal, ${ }^{3}$ Professor, Department of \\ Dermatology, Kasturba Medical College, Manipal, India, ${ }^{4}$ Lecturer, Department of Microbiology, Nobel College, \\ Kathmandu, Nepal
}

Background: Immunobullous disorders are a group of disorders involving the formation of a fluid filled cavity within or beneath the epidermis, due to the presence of autoantibodies against adhesion molecules in epidermis and dermis. Accurate diagnosis of these disorders requires clinicopathological correlation along with immunofluorescence study. Aims and Objectives: This study was undertaken to describe the clinical features of immunobullous disorders and to analyse the utility of Direct immunofluorescence (DIF) in the diagnosis of these disorders. Materials and Methods: A total of 42 Patients attending skin OPD between February 2014 and March 2017 who had a provisional diagnosis of immunobullous disease were enrolled in the study. Detailed clinical examination and DIF study were done in all cases. Results: Out of 42 cases studied, 31 were diagnosed as pemphigus vulgaris (PV) and 11 as bullous pemphigoid (BP) that was confirmed by DIF. There were $20(46.61 \%)$ male patients and $22(52.38 \%)$ female patients in the age group of 18 to 81 years with a mean age of 52.64 years. A slightly female preponderance was observed. Mean age of presentation of PV patients is 50.83 years with age group range was between 18 to 77 years. Majority of patients presented at $4^{\text {th }}$ and $5^{\text {th }}$ decade of life. Age group range for BP was between 34 to 81 years with mean age of presentation being 57.72 years. Majority of our patients presented at $5^{\text {th }}$ decade or later. DIF was positive in all 42 cases $(100 \%)$ of immunobullous disease. DIF in all 31 cases of PV showed $100 \%$ IgG deposition in intercellular substance (ICS) and 64.51\% C3 deposition in ICS. BP showed $100 \%$ C3 deposition in all 11 cases, $63.63 \% \lg$ in seven of the eleven, $18.18 \% \lg A$ in two and $9 \% \operatorname{lgM}$, fibin in one each as a linear band at basement membrane zone (BMZ). Conclusion: Both the clinical findings and the Imunofluorescence features are important in arriving at a definite diagnosis in immunobullous diseases. In all the cases DIF was absolutely essential tool to come to a final diagnosis.

Key words: Immunobullous disorders; Pemphigus; Direct Immnofluorescence

\section{Access this article online}

Website:

http://nepjol.info/index.php/AJMS

DOI: $10.3126 /$ ajms.v12i7.36893

E-ISSN: 2091-0576

P-ISSN: $2467-9100$

Copyright (c) 2021 Asian Journal of Medical Sciences

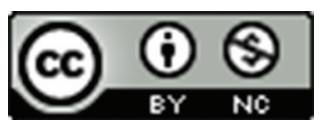

This work is licensed under a Creative Commons Attribution-NonCommercial 4.0 International License.

\section{INTRODUCTION}

Immunobullous disorders are dermatological disorders involving the formation of fluid filled skin blisters as a result of an immunological reaction against different epidermal antigens. Depending on the location of the bulla, these disorders can be classified as intraepidermal, pemphigus group and subepidermal, bullous pemphigoid group. These diseases affect a wide age group though predominantly seen in the elderly. The lesions of the different diseases under this category vary in their clinical appearance and distribution. ${ }^{1}$ To arrive at a diagnosis, clinical examination should be aided by histopathological examination, but a definitive diagnosis can be achieved only using immunofluorescence study. ${ }^{2}$ The aim of this study was to analyse the clinical and immunofluorescence features of immunobullous disorders and to evaluate the diagnostic significance of Direct immunofluorescence (DIF) in these disorders. 


\section{MATERIALS AND METHODS}

A total of 42 Patients attending skin OPD between February 2014 and March 2017 who had a provisional diagnosis of immunobullous disease were enrolled in the study. Written and informed consent were taken. Perilesional Skin biopsy with $3.5 \mathrm{~mm}$ punch for DIF were collected after prior anaesthetization with xylocaine $2 \%$ and sent to pathology Department in Phosphate buffered saline (PBS) where it was stained and seen under immunofluorescence microscope. Approval was obtained from the Institutional Ethics Committee prior to the commencement of the study.

\section{RESULTS}

Out of Forty-two cases of immunobullous diseases thirtyone (31) were diagnosed clinically as pemphigus vulgaris (PV), rest as bullous pemphigoid (BP) attending our OPD between February 2014 and March 2017 were included in the study given in Table 1 . There were Twenty (47.61\%) male patients and Twenty-two $(52.38 \%)$ female patients with male: female ratio of 0.90:1.

The age and sex distribution of immunobullous disease is given in Table 2. In our study, age range was between 18 years to 81 years with a mean age of presentation being 52.64.

Mean age of presentation for men was 53.45 years and for women was 51.9 years. Majority of our patients (34 patients) presented at $4^{\text {th }}$ decade or later; few patients (8 patients) were younger than forty years of age.

The age and sex distribution of PV is given in Table 3 . In our study, age range for PV was between 18 years to 77 years with a mean age of presentation being 50.83 . Mean age of presentation for men was 52.75 years and for women was 48.8 years. Majority of our patients (24 patients) presented at $4^{\text {th }}$ decade or later; few patients (7 patients) were younger than forty years of age.

The age distribution of $\mathrm{BP}$ is given in Table 4. In our study, age range for $\mathrm{BP}$ was between 34 years to 81 years with a mean age of presentation being 57.72. Mean age of presentation for men was 56.25 years and for women was 58.57 years.

\section{Direct immunofluorescence (DIF)}

DIF was positive in all forty-two cases (100\%) of immunobullous disease. Of the 31 patients with clinical diagnosis of PV all (100\%) showed Intercellular space (ICS) deposits in epidermis with IgG (Image 1) and 20 patients (64.51\%) showed $\mathrm{C}_{3}$. The test was negative with other immunoreactants (IgM, $\operatorname{IgA}$, Fibrin). Out of the 31 positive cases of PV, 1 showed strong, 19 showed moderate strong and 11 showed weak ICS deposits with IgG. With $\mathrm{C}_{3}, 9$ showed moderately strong and 11 showed weak ICS deposits (Table 5).

Of the 11 patients with clinical diagnosis of BP all (100\%) showed linear Basement membrane zone (BMZ) band with $\mathrm{C}_{3}$ (Image 2); 7 patients (63.63\%) showed linear BMZ band with IgG. Linear BMZ band was also seen with IgA (2patients), IgM (1patient), fibrin (1patients). Out of the 11 positive cases 3 showed strong and 8 showed moderate strong linear BMZ staining with $\mathrm{C}_{3}$. With $\mathrm{IgG}, 1$ showed strong, 4 showed moderately strong and 2 more showed weak BMZ band. Two patients showed linear BMZ with $\operatorname{IgA}$, one each with IgM and fibrinogen (Table 6).

\begin{tabular}{lcc}
\multicolumn{3}{l}{ Table 1: Types of Immunobullous disease } \\
\hline $\begin{array}{l}\text { Types of } \\
\text { Immunobullous disease }\end{array}$ & $\begin{array}{c}\text { Number of } \\
\text { patients }\end{array}$ & Percentage \\
\hline Pemphigus vulgaris (PV) & 31 & $73.80 \%$ \\
Bullous pemphigoid (BP) & 11 & $26.19 \%$ \\
Total & 42 & \\
\hline
\end{tabular}

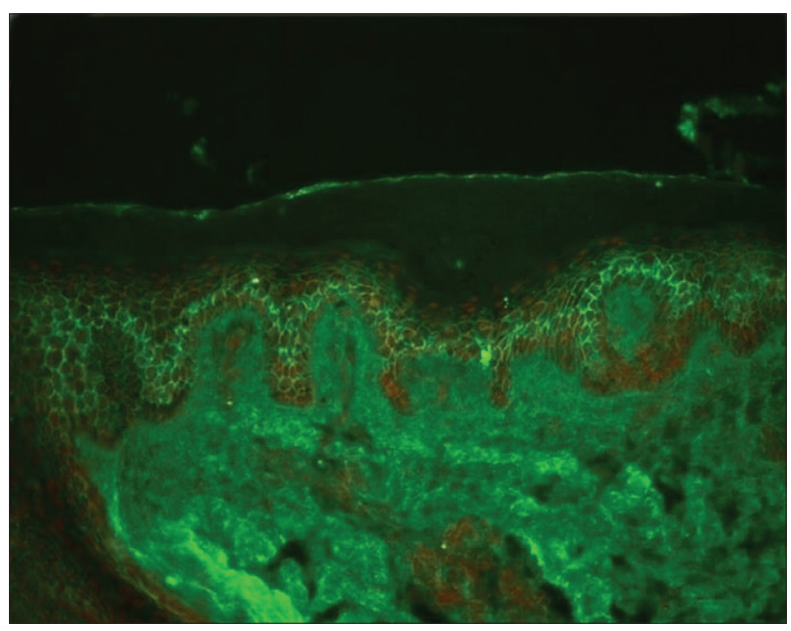

Image 1: PV - DIF: Intercellular space (ICS) IgG deposits throughout epidermis

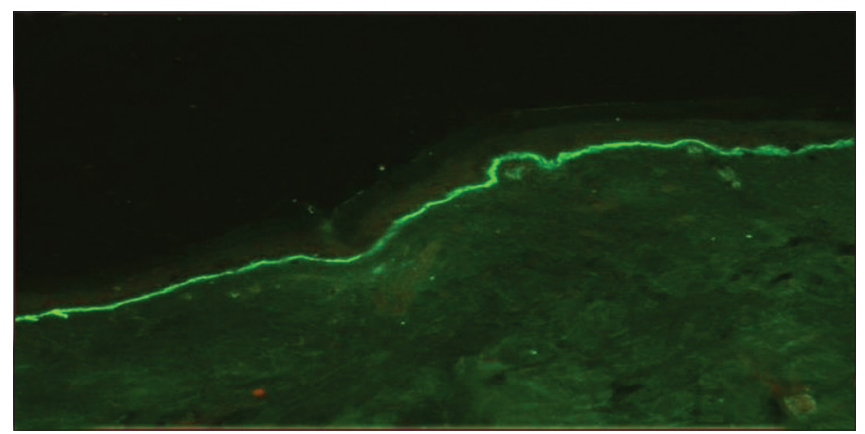

Image 2: BP - DIF: Linear basement membrane zone (BMZ)) deposits of $\mathrm{C} 3$ 


\begin{tabular}{|c|c|c|c|c|c|c|}
\hline Age & $1-20$ & $21-30$ & $31-40$ & $41-50$ & $51-60$ & $>60$ \\
\hline Male & 1 & 0 & 2 & 6 & 3 & 8 \\
\hline Female & 0 & 1 & 4 & 5 & 8 & 4 \\
\hline Total & $1(2.38 \%)$ & $1(2.38 \%)$ & $6(14.28 \%)$ & $11(26.19 \%)$ & $11(26.19 \%)$ & $12(28.57 \%)$ \\
\hline
\end{tabular}

\begin{tabular}{|c|c|c|c|c|c|c|}
\hline Age & $1-20$ & $21-30$ & $31-40$ & $41-50$ & $51-60$ & $>60$ \\
\hline Male & 1 & 0 & 2 & 5 & 1 & 7 \\
\hline Female & 0 & 1 & 3 & 4 & 5 & 2 \\
\hline Total & $1(3.22 \%)$ & $1(3.22 \%)$ & $5(14.28 \%)$ & $9(29.03 \%)$ & $6(19.35 \%)$ & $9(29.03 \%)$ \\
\hline
\end{tabular}

\begin{tabular}{|c|c|c|c|c|c|c|}
\hline Age & $1-20$ & $21-30$ & $31-40$ & $41-50$ & $51-60$ & $>60$ \\
\hline Male & 0 & 0 & 0 & 1 & 2 & 1 \\
\hline Female & 0 & 0 & 1 & 1 & 3 & 2 \\
\hline Total & $0(0.00 \%)$ & $0(0.00 \%)$ & $1(9.09 \%)$ & $2(18.18 \%)$ & $5(45.45 \%)$ & $3(27.27 \%)$ \\
\hline
\end{tabular}

\begin{tabular}{lccccc} 
Table 5: DIF findings of PV & \\
\hline Intensity & IgG & C3 & IgA & IgM & Fibrin \\
\hline Strong $(+++)$ & 1 & 0 & 0 & 0 & 0 \\
Moderately strong $(++)$ & 19 & 9 & 0 & 0 & 0 \\
Weak $(+)$ & 11 & 11 & 0 & 0 & 0 \\
Total & $31(100 \%)$ & $20(64.51 \%)$ & $0(00.0 \%)$ & $0(00.0 \%)$ & $0(00.0 \%)$ \\
\hline
\end{tabular}

\begin{tabular}{|c|c|c|c|c|c|}
\hline Intensity & $\lg G$ & C3 & $\lg A$ & $\lg M$ & Fibrin \\
\hline Strong $(+++)$ & 1 & 3 & 1 & 1 & 0 \\
\hline Moderately strong $(++)$ & 4 & 8 & 1 & 0 & 1 \\
\hline Weak (+) & 2 & 0 & 0 & 0 & 0 \\
\hline Total & $7(63.63 \%)$ & $11(100 \%)$ & $2(18.18 \%)$ & $1(9.0 \%)$ & $1(9.0 \%)$ \\
\hline
\end{tabular}

Lesion in pemphigus vulgaris showing Multiple flaccid vesicles, bulla and erosions was observed (Image 3). Image 4 showed the lesion in Bullous pemphigoid.

\section{DISCUSSION}

We investigated the clinical and immunofluorescence findings of 42 cases who presented with immunobullous diseases. Out of 42 cases, 31 were diagnosed as PV and 11 as BP that was confirmed by DIF. There were $20(46.61 \%)$ male patients and $22(52.38 \%)$ female patients in the age group of 18 to 81 years with a mean age of 52.64 years in our study. A slightly female preponderance was observed. Male to female ratio was $0.90: 1$. Mean age of presentation of PV patients is 50.83 years with age group range was between 18 to 77 years. Majority of patients presented at $4^{\text {th }}$ and $5^{\text {th }}$ decade of life. Youngest patient was 18 years old and eldest patients was 77 years old indicating that pemphigus is seen over a wide age distribution. Similar observation was made by Krain LS et al., ${ }^{3}$ in a previous

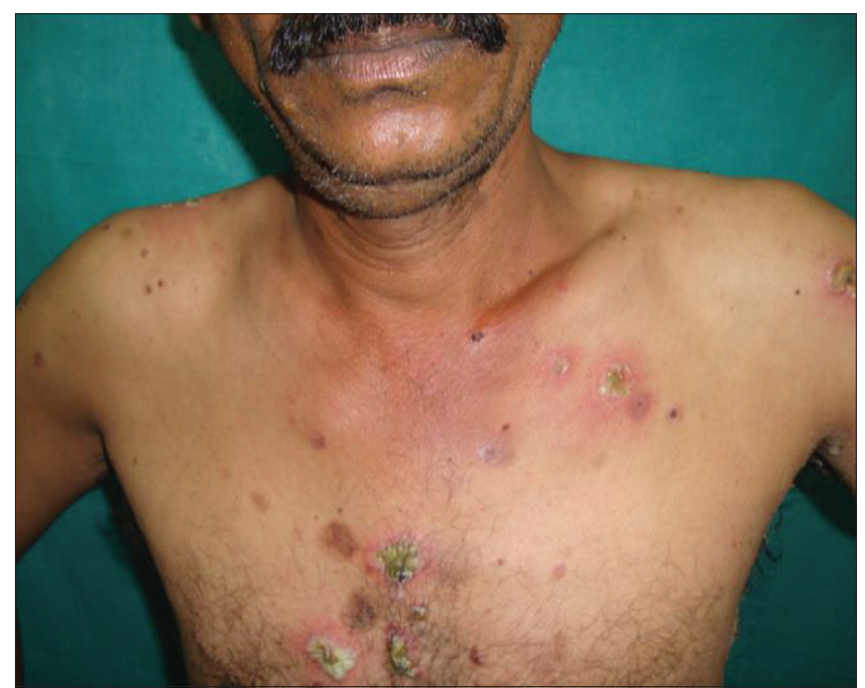

Image 3: Lesion in pemphigus vulgaris: Multiple flaccid vesicles, bulla and erosions can be noted on the Chest areas

study. This is in contrast to study done by Sehgal VN et al., peak age of onset in the $3^{\text {rd }}$ and $4^{\text {th }}$ decade. ${ }^{4}$ Age group 


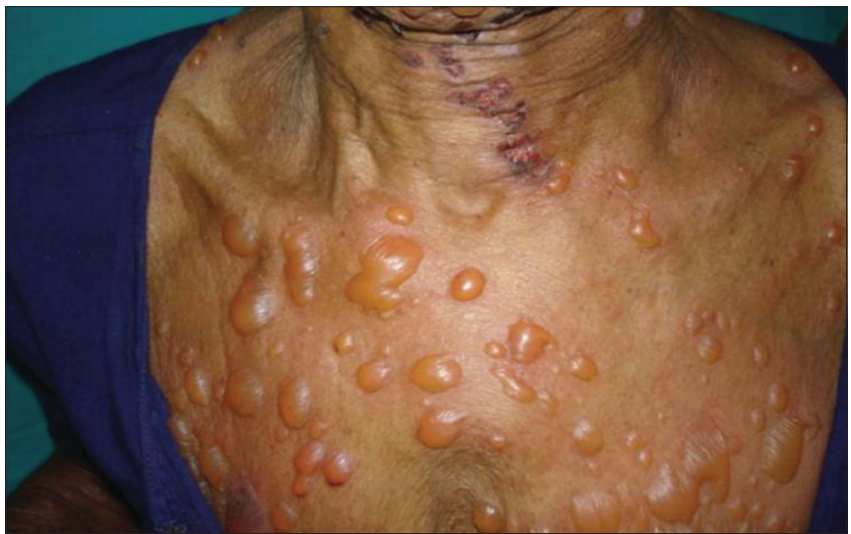

Image 4: Lesion in Bullous pemphigoid - Large tense bulla can be noted on the chest areas

range for $\mathrm{BP}$ was between 34 to 81 years with mean age of presentation being 57.72 years in contrast to previous study mean age of presentation ranges from 60 to 75 years. ${ }^{5}$ Majority of our patients presented at $5^{\text {th }}$ decade or later.

After clinical and immunofluorescence studies the commonest immunobullous disease found in our hospital was PV (73.80\%) and BP (26.19\%). The blisters formed on skin and mucous membrane are classified according to their size as vesicles and bullae. Patients with PV mostly presented with flaccid vesicles and bulla with surrounding areas showing denuded areas caused by rupture and erosion with Oral mucosal involvement (Image 3). BP presented with characteristic large tense bulla placed on urticarial erythematous base or non-erythematous skin (Image 4). PV accounts for approximately $70 \%$ of all cases of intraepidermal bullous disease and may be the most common autoimmune blistering disease in eastern countries, such as India, Malaysia, China, and the middle east. ${ }^{6,7} \mathrm{PV}$ is more common in Indians than in black or white races. ${ }^{8}$ Study conducted by Wong et al., ${ }^{9}$ and Nanda et al., ${ }^{10}$ found that BP was commonest cause of sub epidermal bullous disease (SEBD) ranges from $40 \%$ to $88 \%$. Peiying et al., ${ }^{11}$ reviewed cases of SEBD in between 1953 to 1991 and found out most common type of bullous disease is $\mathrm{BP}(54 \%)$ followed by EBA (8\%), LABD (7\%), and cicatrical pemphigoid (3\%). We did not encounter any other types during the study period.

The evidence suggesting pemphigus as an autoimmune disease was given by Buetner et al., when they described circulating and tissue bound IgG antibodies in the intercellular cement substances. ${ }^{12}$ DIF of perilesional skin is virtually positive in $100 \%$ of patients with active disease. ${ }^{13}$ We have included cases of PV after confirmed diagnosis by DIF, so it is positive in $100 \%$ in our study. We could detect IgG in $100 \%$ and C3 in $64.51 \%$ of our patients. However, none of the patients were tested positive for other immunorectants. Previous study showed IgG are the most common subclasses. Complement component(C3), $\operatorname{IgM}$, and $\operatorname{IgA}$ are present less frequently than $\operatorname{IgG}{ }^{14}$ In addition to IgG, IgA, IgM and C3 were also found in 30$50 \%$ of patients in previous study. ${ }^{15} \mathrm{IgG} 1$ seems to be the most sensitive indicator for activity of the disease. IgG4, normally found in the lowest concentration in human serum, is the most common subclass in patients who are in remission. IgG4 and C3 may have a predictive value for remission. ${ }^{16}$

In BP patients, C3 was positive in 100\% cases where as $\mathrm{IgG}$ was found positive in seven of the eleven (63.63\%) in DIF. Other immunoreactants IgA positive in two $(18.18 \%)$, $\operatorname{IgM}$ and fibin in one $(9 \%)$ each in our study. Hadi Smet et al., found C3 in nearly all (100\%) specimen, of IgG in $90 \%$ and IgA and IgM in about $25 \%$ each. ${ }^{17,18}$ This is also in consistence with the findings of Satyapal et al., who found C3 alone or in combination with other immunoreactants in $90 \%$ of cases. $^{19}$

\section{CONCLUSIONS}

PV was the commonest immunobullous disease in our hospital followed by BP. We did not encounter any other types during the study period. PV and BP are a disease of elderly and mean age of presentation was 50.83 and 57.83 years in our study. Immunobullous disease was slightly more common among female's compared to male patients $(52.38 \%$ Vs $47.61 \%)$ in our study. Most common immunoreactants was IgG (100\%) followed by C3 (64.51\%) in case of PV where as in BP most common immunoreactants was C3 (100\%) followed by IgG (63.63\%) in DIF studies. DIF were positive in all patients $(100 \%$ sensitivity) in our study confirming the fact that it is a gold standard in the diagnosis of immunobullous diseases.

\section{REFERENCES}

1. Chandrashekar M, Leena JB, Vijaya B, Sunila R and Manjunath GV. A clinicopathological study of immunobullous lesions of the skin a 2 years study. Annals of Pathology and Laboratory Medicine. 2012; 1:19-26.

2. Huilgol SC, Bhogal BS and Black MM. Immunofluorescence of the immunobullous disorders Part two: The clinical disorders. Indian J Dermatol Venereol Leprol. 1995; 61:255-264.

3. Krain LS. Pemphigus: Epidemiology and survival characteristic of 59 patients. Arch Dermatology. 1974;110: 862-865. https://doi.org/10.1001/archderm.1974.01630120012002

4. Sehgal VN. Pemphigus in India: A note. Indian J Dermatol 1972;18:5-7.

5. Nemeth AJ, Klein AD, Gould EW and Schachner LA. Childhood bullous Pemphigoid: Clinical and immunological features, treatment and prognosis. Arch Dermatol.1991;127: 378-386.

6. Wilson C, Wojnarowska F, Mehra NK and Pasricha JS. 
Pemphigus in oxford, UK, and New Delhi, India: a comparative study of disease characteristics and HLA antigen. Dermatology. 1994;189 (suppl.1):108-110. https://doi.org/10.1159/000246946

7. Adam BA. Bullous disease in Malaysia: Epidemiology and Natural history. Int J Dermatol. 1992;31: 42-45. https://doi.org/10.1111/j.1365-4362.1992.tb03519.x

8. Aboobaker J, Morar N, Ramdial PK and Hammond MG. Pemphigus in south Africa. Int J Dermatol. 2001; 40:115-119. https://doi.org/10.1046/j.1365-4362.2001.01124.x

9. Wong $S$ and Chua $S$. Spectrum of subepidermal immunobullous disorder seen at national skin centre, Singapore: a 2-year review. Br J Dermatol. 2002; 147:476-480.

https://doi.org/10.1046/j.1365-2133.2002.04919.x

10. Nanda A, Dvorak R, Al-Saeed K, Al-Sabah H, Alsaleh QA Spectrum of autoimmune bullous diseases in Kuwait. Int $\mathrm{J}$ Dermatol. 2004; 43: 876-881. https://doi.org/10.1111/j.1365-4632.2004.02292.x

11. Jin P, Shao $C$ and Ye G. Chronic bullous dermatoses in China. Int J Dermatol. 1993;32 (2):89-92.

12. Stanley RJ. Pemphigus in: Fitzpatrick TB, Eisen EZ, Wolff K et al Ed Dermatology in General Medicine, $6^{\text {th }}$ edition New York: Mc Graw Hill 2003;1:558-561.
13. Cooperative study: use of immunofluorescence tests of skin and sera. Arch Dermatol 1975;111: 371-381.

14. Helander KE and Roger RS III. The sensitivity and specificity of direct immunofluorescence testing in disorder of mucous membranes. J Am Acad Dermatol. 1994;30: 65-75. https://doi.org/10.1016/S0190-9622(94)70010-9

15. Judd KP and Lever WF. Correlation of antibodies in skin and serum with disease severity in pemphigus. Arch Dermatol. 1979; 115: 428-432. https://doi.org/10.1001/archderm.1979.04010040006002

16. David M and Katzenelson V. Determination of IgG Subclasses in Patients with Pemphigus with Active Disease and in Remission. Arch Dermatol.1989;125: 787-790. https://doi.org/10.1001/archderm.1989.01670180059006

17. Hadi SM and Barneton RSC. Clinical histological and immunologic studies in 50 patients with bullous pemphigoid. Dermatologica. 1988;176: 6-17. https://doi.org/10.1159/000248663

18. Ahmed AR, Maize JC and Piovost TT. Bullous pemphigoid. Clinical and immunological follow up after successful therapy. Arch Dermatol.1977;113:1043-1046.

19. Satyapal S, Amladi S and Jerajani H. Evaluation of salt split technique of immunofluorescence in bullous pemphigoid. Indian J Dermatol Venereol Leprol. 2002; 68:330-333.

\section{Author's Contribution:}

NRP, RR- Concept and design of the study,prepared first draft of the manuscript, interpreted the results, reviewed the literature; ADP-Specimen preparation and reporting; RR-Revision of manuscript, final approval; SK-coordination, interpretation of results, final manuscript preparation.

\section{Work Attributed to:}

Grande International Hospital (GIH), Kathmandu, Nepal.

\section{Orcid ID:}

Dr. Nitesh R. Pokharel- (1) https://orcid.org/0000-0003-3611-3296

Surakchya Koirala- (1) https://orcid.org/0000-0003-2011-4948

Source of Funding: None, Conflict of Interest: None. 